\title{
Conhecimentos e práticas de professores de educação infantil sobre crianças com alterações auditivas
}

\author{
Knowledge and practice of preschool teachers regarding \\ children with hearing alterations
}

\author{
Denísia Raquel de Carvalho Silva ${ }^{1}$, Lílian Marinho dos Santos², Stela Maris Aguiar Lemos ${ }^{3}$, Sirley Alves da Silva \\ Carvalho $^{4}$, Renata Martinelli Perin ${ }^{5}$
}

\begin{abstract}
RESUMO
Objetivo: Investigar os conhecimentos, as percepções e as práticas de professores de educação infantil sobre crianças com alterações auditivas. Métodos: Estudo descritivo transversal, realizado por meio de entrevista estruturada com 45 professores de educação infantil da rede pública de ensino da cidade de Belo Horizonte. As entrevistas foram gravadas, transcritas e posteriormente submetidas à análise. Resultados: A grande maioria dos sujeitos entrevistados apresentou pouco conhecimento, muitas vezes bastante vago e de senso comum, sobre a perda auditiva, embora a consciência da necessidade de aprendizagem para uma melhor atuação profissional tenha sido nítida. Apesar da falta de informação, os professores demonstraram conhecer algumas características das crianças com deficiência auditiva e explicitaram condutas a serem realizadas em sala de aula. A quase totalidade da amostra afirmou não conhecer a triagem auditiva escolar. Conclusão: Os conhecimentos, as práticas e as percepções demonstradas pelos entrevistados revelaram grande variação de conceitos, atitudes e estratégias. Contudo, grande parte se baseia em senso-comum ou intuição, devido à falta de experiência e de capacitação dos educadores para lidar com a criança com deficiência auditiva.
\end{abstract}

Descritores: Docentes; Linguagem infantil; Educação infantil; Desenvolvimento infantil; Perda auditiva; Promoção da saúde; Saúde escolar

\section{INTRODUÇÃO}

O encontro entre Fonoaudiologia e Educação é promissor e tem contribuído para a elaboração, implantação e avaliação de estratégias de promoção da saúde e de prevenção de distúrbios da comunicação humana. Contribui também para desenvolvimento e implantação de ações voltadas à inclusão de alunos com necessidades especiais. Entende-se que a principal fundamentação na condução dessas ações no ambiente escolar

Trabalho realizado no Departamento de Fonoaudiologia da Faculdade de Medicina da Universidade Federal de Minas Gerais - UFMG - Belo Horizonte (MG), Brasil.

(1) Acadêmica do Curso de Fonoaudiologia da Universidade Federal de Minas Gerais - UFMG - Belo Horizonte (MG), Brasil.

(2) Acadêmica do Curso de Fonoaudiologia da Universidade Federal de Minas Gerais - UFMG - Belo Horizonte (MG), Brasil.

(3) Doutora, Professora Adjunto do Curso de Fonoaudiologia da Universidade Federal de Minas Gerais - UFMG - Belo Horizonte (MG), Brasil.

(4) Doutora, Professora Adjunto do Curso de Fonoaudiologia da Universidade Federal de Minas Gerais - UFMG - Belo Horizonte (MG), Brasil.

(5) Pós-graduanda (Especialização) em Linguagem da Pontifícia Universidade Católica de Minas Gerais - PUC-MG - Belo Horizonte (MG), Brasil.

Endereço para correspondência: Stela Maris Aguiar Lemos. Av. Prof. Alfredo Balena, 190/sala 069, Belo Horizonte (MG), Brasil, CEP: 30100-130.

E-mail: smarislemos@medicina.ufmg.br

Recebido em: 13/2/2009; Aceito em: 28/9/2009 deve passar pelo diálogo entre professores e fonoaudiólogos. Assim, o fonoaudiólogo é capaz de redimensionar suas possibilidades de atuação junto à escola, usando como referencial a promoção da saúde ${ }^{(1)}$.

A legislação brasileira garante a inclusão de alunos com necessidades especiais em classes regulares ${ }^{(2)}$. Entretanto, para a garantia deste direito, é necessária a identificação de crianças com tais necessidades. Importante ressaltar que há dificuldades perpassando a inclusão, desde o diagnóstico de crianças com alterações até a capacitação dos profissionais que com elas lidam ${ }^{(3)}$.

Sabemos que o desenvolvimento infantil é influenciado por condições biológicas, ambientais, econômicas e sociais, que estão relacionadas, também, às oportunidades de aprendizagem, ao desenvolvimento de habilidades e à construção de conhecimentos. Nesse contexto, a audição é de suma importância para o desenvolvimento de crianças e adolescentes no que tange à vida escolar e à social ${ }^{(4)}$. Além disso, nessa fase, toda criança encontra-se sujeita a morbidades e agravos decorrentes de fatores pessoais e ambientais, que interferem direta e indiretamente no aprendizado. Quase todas desenvolverão algum período de perda auditiva relacionada a infecções na orelha nos primeiros dez anos de idade ${ }^{(5)}$. Estudos relatam que cerca de $80 \%$ das crianças têm pelo menos um episódio de 
otite média serosa (OMS) até os oito anos de idade ${ }^{(6)} \mathrm{e}$, apesar de, na sua maioria, causar uma perda leve, é suficiente para dificultar o aprendizado(7).

Qualquer tipo de alteração auditiva, independentemente do grau ou tipo, acarreta sérias alterações no desenvolvimento global da criança. Assim, o diagnóstico da deficiência auditiva deve ser o mais precoce possível e, nesse sentido, as Políticas de Saúde Pública têm preconizado atenção diagnóstica e terapêutica especializada às pessoas com ou sem risco ou suspeita de deficiência auditiva, por meio da oferta de triagem e monitoramento da audição de neonatos, pré-escolares e escolares ${ }^{(8-10)}$.

Quando a perda auditiva é severa ou profunda, é mais fácil de ser diagnosticada. Quando se trata de perda parcial (permanente ou transitória) de grau leve a moderado, o diagnóstico é mais difícil, entretanto os prejuízos acarretados no aprendizado são significativos ${ }^{(5)}$. Frequentemente, tais tipos de perda passam despercebidas por não existir um trabalho sistematizado de detecção e seguimento de casos, o que requer ação conjunta entre profissionais de saúde, professores e pais ${ }^{(1)}$.

A incidência de perda auditiva bilateral significante em neonatos saudáveis é estimada entre um a três neonatos em cada 1000 nascimentos e em cerca de 2 a $4 \%$ nos provenientes de Unidades de Terapia Intensiva. Devido à elevada prevalência de perda, constitui-se em um verdadeiro problema de saúde pública ${ }^{(9)}$.

No Brasil, dados mostram que o diagnóstico e intervenção ocorrem em idade muito tardia ${ }^{(11)}$, em torno de quatro anos de idade $^{(12)}$. Tal realidade, contudo, vem mudando com a expansão dos programas de triagem auditiva e consequentemente o diagnóstico tem sido mais precoce ${ }^{(13,14)}$.

Os problemas auditivos leves ou moderados passam despercebidos por pais e professores, em um grande número de casos. Por isso mesmo, a triagem no período escolar demonstra ser a forma mais eficaz de detectar tais alterações. Contudo, o fonoaudiólogo deve transpor os limites tradicionais da prática clínica, que atua no indivíduo quando os agravos já estão instalados, para alcançar a meta da promoção e vigilância à saúde ${ }^{(15)}$.

Estudos comprovam a relação direta entre alterações auditivas e queixas relacionadas à linguagem e desempenho escolar. Os distúrbios da comunicação, dentre eles a perda auditiva, podem manifestar-se por meio de sinais e sintomas observáveis por pessoas que lidam diariamente com a criança, desde que devidamente preparadas. É o caso do professor de classe, que tem como obrigação inerente à profissão, ensinar e promover o bem-estar da criança, o que inclui melhores condições de aprendizagem ${ }^{(16)}$.

A qualificação e a atenção dos profissionais da saúde e do ensino para a perda auditiva possibilitam tanto a prevenção quanto um encaminhamento precoce e adequado dos casos suspeitos. Disso pode resultar o tratamento das causas da doença e as adaptações fonoaudiológicas, sociais e escolares necessárias à compensação da perda auditiva ${ }^{(17)}$. Como se vê, é de suma importância a implementação de programas de promoção da saúde no ambiente escolar ${ }^{(18)}$.

Sabe-se que, antes de qualquer intervenção relacionada à promoção da saúde, é necessário avaliar o conhecimento da população para a qual se pretende promover a ação. É importante verificar, além de percepções, os conhecimentos e concepções das pessoas que irão lidar com crianças com necessidades especiais. Estudos revelam o sentimento de despreparo dos educadores e a necessidade de avanços em conhecimentos, competências e habilidades docentes para a efetivação do processo inclusivo ${ }^{(19-22)}$.

Há, portanto, um vasto campo a ser atingido, e a Fonoaudiologia tem obrigação de contribuir no diálogo e na concretização de ações que efetivem a inclusão de crianças com necessidades especiais no ambiente escolar ${ }^{(23)}$.

O presente estudo teve como objetivo investigar os conhecimentos, percepções e práticas dos professores de educação infantil da Rede Municipal de Belo Horizonte sobre crianças com alterações auditivas.

\section{MÉTODOS}

Trata-se de um estudo descritivo transversal, aprovado pelo Comitê de Ética em Pesquisa da Universidade Federal de Minas Gerais (UFMG), com parecer n ${ }^{\circ}$ ETIC 305/05.

\section{Sujeitos e cenário do estudo}

Participaram deste estudo 45 professores de educação infantil de cinco Unidades Municipais de Educação Infantil (UMEI) da rede pública de ensino da cidade de Belo Horizonte, correspondendo a 11,3\% do total de UMEIs deste município. As escolas foram selecionadas por sorteio entre as Regionais da Secretaria Municipal de Educação.

As escolas selecionadas para o estudo atendem, em média, 233 alunos de quatro a seis anos de idade. De acordo com a política de inclusão social, elas integram crianças com deficiência auditiva em seu quadro de matriculados. No momento da pesquisa, cada escola acolhia de uma a duas crianças com suspeita ou perda auditiva diagnosticada.

O quadro de educadores de cada escola é composto em média por 28 professores, 14 por turno. Cada professor é responsável por classes com aproximadamente 15 alunos. Foi entrevistada uma média de nove professores por escola, representando $32,14 \%$ do quadro total de professores, e $64,2 \%$ do turno no qual a pesquisa foi efetuada.

\section{Critérios de inclusão}

Foram considerados critérios de inclusão: ser professor efetivo da rede municipal de Belo Horizonte; ter idade igual ou superior a 18 anos; concordar com o Termo de Consentimento Livre e Esclarecido.

\section{Instrumento e coleta de dados}

Foram realizadas entrevistas com roteiro estruturado, adaptado da proposta de Cristofolini e Magni ${ }^{(1)}$. A adaptação foi feita com a inclusão de uma questão acerca do conhecimento sobre a triagem auditiva em escolares. Desse modo, o roteiro constou de seis questões (Anexo 1).

As entrevistas foram realizadas individualmente no próprio local de trabalho do professor e tiveram duração média de 30 minutos. Foram gravadas em áudio e, posteriormente, transcritas para análise dos dados. 
Em relação à caracterização da amostra, verificamos que 97,05\% dos professores eram do sexo feminino e 2,95\%, do sexo masculino. Quanto à qualificação profissional, verificamos que $89,7 \%$ dos professores possuíam o ensino superior e $10,3 \%$ o magistério. Quanto à experiência em educação infantil, encontramos 45,58\% com experiência de um a cinco anos; $26,47 \%$, de seis a dez anos; $14,7 \%$, de 11 a 15 anos; $13,23 \%$ tinham mais de 15 anos de experiência na área.

\section{Análise dos dados}

Para o estudo, foi realizada análise quantitativa descritiva das questões de caracterização da amostra e questões com característica binária da resposta ( $\operatorname{sim} /$ não): se o professor trabalhou na sala de aula com crianças portadoras de deficiência auditiva e se este conhece a triagem auditiva realizada em crianças em idade escolar; ou pela característica objetiva da resposta: para qual profissional o professor encaminharia uma criança com suspeita de deficiência auditiva.

Nesse estudo, optamos por utilizar a análise de conteúdo dos discursos, metodologia de análise de textos que parte de uma perspectiva quantitativa, analisando-se numericamente a frequência de ocorrência de determinados termos, construções ou referências. A fundamentação foi a Análise de Conteúdo, proposta por Bardin ${ }^{(24)}$. As idéias centrais das respostas de uma mesma questão foram identificadas para posterior comparação do grupo e síntese do conhecimento geral. Após a seleção das categorias a serem analisadas em cada questão, verificamos a sua frequência de ocorrência (aparecimento) nos discursos dos sujeitos.

Importante relatar que a pretensão inicial era distribuir a população em dois grupos: professores com experiência de atuação com crianças com deficiência auditiva e professores sem experiência. Essa distribuição seria pautada na questão "Você já trabalhou na sala de aula com crianças portadoras de deficiência auditiva?". Contudo, a análise dos conteúdos do conjunto de respostas de cada professor revelou que, dos 12 sujeitos que referiram ter vivenciado tal atuação, apenas dois referiram ter conhecimento de como trabalhar com crianças com deficiência auditiva. Revelou, ainda, que não existiam diferenças significativas nas respostas dos entrevistados. Assim, optou-se por realizar a análise de dados da população total e, na discussão dos resultados, quando pertinente, apresentar e confrontar as respostas dos dois sujeitos com conhecimento e o restante da amostra.

Cabe ressaltar que, nos resultados e na discussão, além da análise do conteúdo das respostas, foram apresentadas vinhetas das falas dos entrevistados, com o objetivo de ilustrar e consubstanciar a discussão dos temas.

\section{RESULTADOS}

Doze sujeitos, ou 27\%, trabalharam ou trabalham com crianças com deficiência auditiva em sala de aula. Desses, apenas dois $(0,9 \%)$ apresentaram respostas satisfatórias, quanto às características do deficiente auditivo e à conduta em sala com essa população.

No Quadro 1, são apresentadas as categorias, conteúdos, frequências e vinhetas referentes às respostas dos entrevistados, quanto ao conhecimento acerca da deficiência auditiva.

No Quadro 2, destacam-se as respostas dos participantes da pesquisa em relação a que características eles percebem em crianças com deficiência auditiva.

No Quadro 3, estão expostas as categorias, conteúdos, frequências e vinhetas referentes às respostas acerca da conduta, em sala de aula, com uma criança com deficiência auditiva.

Na Figura 1, são apresentados os profissionais, citados pelos professores, para quem encaminhariam a criança com suspeita de deficiência auditiva.

No que diz respeito ao conhecimento dos professores a respeito de Triagem Auditiva realizada nas escolas, 95\% dos entrevistados relataram desconhecer esse processo.

\section{DISCUSSÃO}

Acredita-se que o professor seja um agente de extrema importância na identificação da criança com alguma deficiência

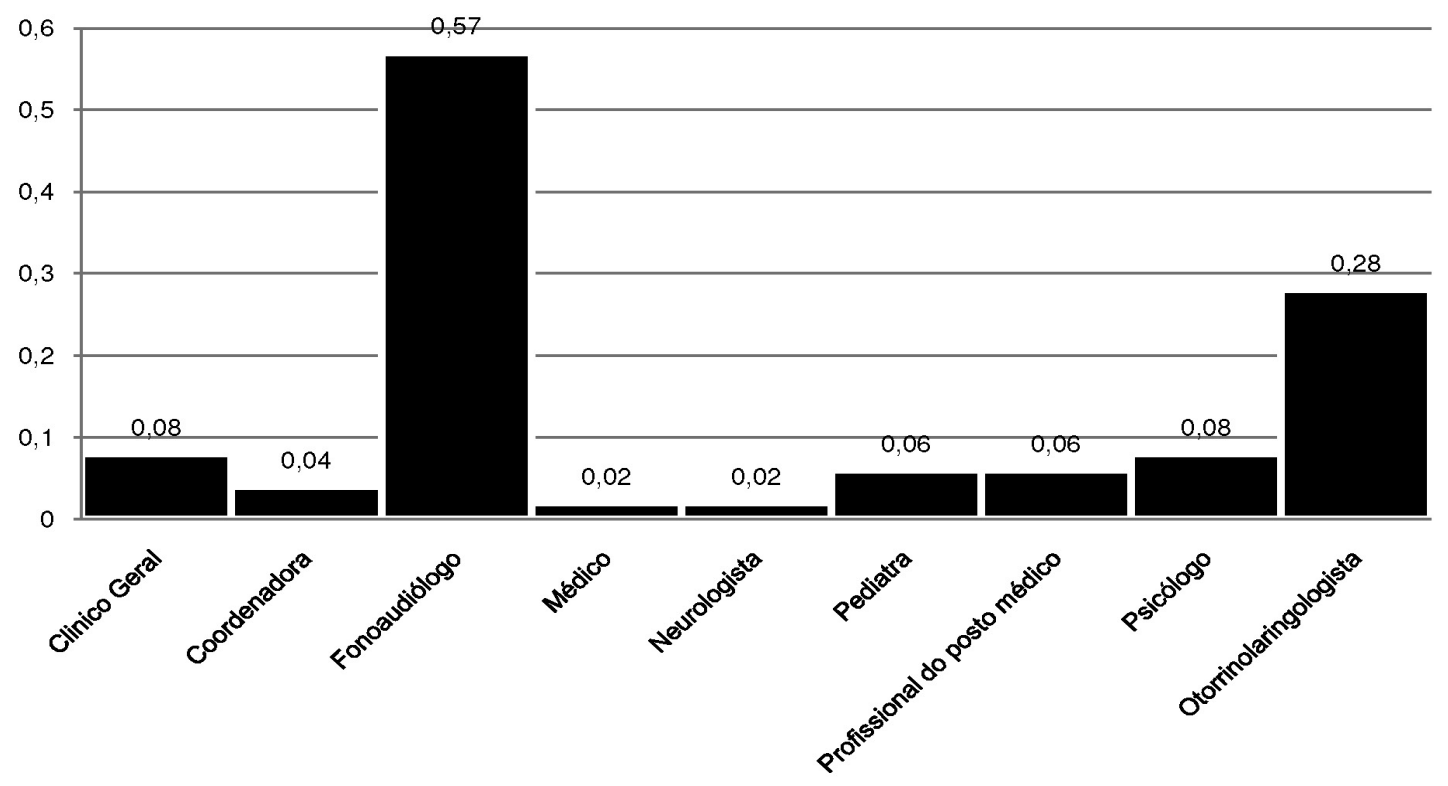

Figura 1. Alternativas de encaminhamento 
Quadro 1. Relatos dos professores quanto ao conhecimento da deficiência auditiva

\begin{tabular}{|c|c|c|c|}
\hline Categoria & Conteúdo & Frequência & Vinheta \\
\hline $\begin{array}{l}\text { Respostas que evidenciam quantidade de } \\
\text { conhecimento }\end{array}$ & $\begin{array}{c}\text { Pouco } \\
\text { Quase nada } \\
\text { Muito pouco } \\
\text { Nada } \\
\text { Alguma coisa }\end{array}$ & $\begin{array}{c}2 \\
5 \\
15 \\
10 \\
1\end{array}$ & $\begin{array}{c}\text { "Eu não tenho experiência nenhuma não conheço nada } \\
\text { assim para trabalhar com criança relacionada a isso eu } \\
\text { não conheço nada." }\end{array}$ \\
\hline $\begin{array}{l}\text { Respostas que evidenciam vivência/ } \\
\text { experiência pessoal }\end{array}$ & $\begin{array}{l}\text { Parentes surdos } \\
\text { Contato com } \\
\text { profissionais } \\
\text { Portador de } \\
\text { deficiência auditiva }\end{array}$ & $\begin{array}{l}2 \\
3 \\
1\end{array}$ & $\begin{array}{l}\text { “...eu conheço várias coisas a respeito do assunto, eu } \\
\text { tenho na família médicos, minha irmã é pediatra, então é } \\
\text { mais fácil esse vocabulário de deficiência auditiva..." }\end{array}$ \\
\hline $\begin{array}{l}\text { Respostas que evidenciam vivência/ } \\
\text { experiência baseada em ambiente de trabalho } \\
\text { ou acadêmico }\end{array}$ & $\begin{array}{c}\text { Contato com alunos } \\
\text { da escola } \\
\text { Curso de Pedagogia } \\
\text { Textos da faculdade } \\
\text { Curso de LIBRAS } \\
\text { Curso de } \\
\text { Psicopedagogia }\end{array}$ & $\begin{array}{l}4 \\
\\
5 \\
2 \\
1 \\
1\end{array}$ & $\begin{array}{c}\text { "...na faculdade a gente lê alguns textos, mas que não } \\
\text { tem um embasamento pra gente saber o que é essa } \\
\text { deficiência auditiva..." }\end{array}$ \\
\hline $\begin{array}{l}\text { Respostas que evidenciam conceitos apoiados } \\
\text { em senso comum }\end{array}$ & Senso comum & 3 & $\begin{array}{l}\text { "Bem sobre deficiência auditiva o que nós conhecemos é } \\
\text { praticamente os nortes que temos do senso comum." }\end{array}$ \\
\hline $\begin{array}{l}\text { Respostas que evidenciam conceitos apoiados } \\
\text { em características do surdo }\end{array}$ & Perfil do surdo & 9 & $\begin{array}{c}\text { “..eu vejo que muitas vezes são assim dispersas, elas, } \\
\text { elas não interagem com os outros grupos...” }\end{array}$ \\
\hline $\begin{array}{l}\text { Respostas que evidenciam conceitos apoiados } \\
\text { nas alterações de audição e comunicação }\end{array}$ & $\begin{array}{c}\text { Impossibilidade } \\
\text { de compreensão } \\
\text { sonora/dificuldade de } \\
\text { audição } \\
\text { Uma síndrome } \\
\text { Leituras sobre o tema } \\
\text { Não sabe falar }\end{array}$ & $\begin{array}{l}9 \\
\\
1 \\
2 \\
1\end{array}$ & $\begin{array}{c}\text { "Ah, eu acredito que seja uma dificuldade de audição ou } \\
\text { talvez uma síndrome..." }\end{array}$ \\
\hline $\begin{array}{l}\text { Respostas que evidenciam conhecimento } \\
\text { apoiado em leitura }\end{array}$ & Leituras prévias & 2 & $\begin{array}{l}\text { “...eu nunca trabalhei com crianças com deficiência, } \\
\text { então eu mais leio, leio alguma coisa a respeito..." }\end{array}$ \\
\hline $\begin{array}{l}\text { Respostas que evidenciam atitudes frente ao } \\
\text { surdo }\end{array}$ & $\begin{array}{l}\text { Apoio em gestos } \\
\text { Aumento de } \\
\text { articulação } \\
\text { Aproximação física } \\
\text { Posicionamento }\end{array}$ & $\begin{array}{l}1 \\
1 \\
1\end{array}$ & $\begin{array}{l}\text { "... a gente tem que falar pra criança ou pra pessoa que } \\
\text { tem problema de audição né, gesticulando é mexendo } \\
\text { bem com a boca...” }\end{array}$ \\
\hline Não soube responder & - & 1 & $\begin{array}{l}\text { "... com deficiência auditiva eu ainda não trabalhei, então } \\
\text { eu não sei falar a respeito da deficiência auditiva." }\end{array}$ \\
\hline
\end{tabular}

sensorial, principalmente visual e auditiva. Os conhecimentos desse profissional em relação às deficiências sensoriais estão diretamente ligados às suas condutas e, consequentemente, disso depende a vida escolar e posterior inserção social do indivíduo. Entretanto, pôde-se verificar neste estudo que a grande maioria dos sujeitos entrevistados apresenta, frequentemente, conhecimento vago, escasso e de senso comum sobre a perda auditiva.

Segundo dados da literatura ${ }^{(25)}$, o professor detém a tarefa precípua de transmissão de conhecimentos na escola, que pode incluir a orientação em saúde ocular para alunos e familiares. Em razão disso, entende-se que a orientação referente à saúde auditiva deve passar pelo mesmo processo.

Para a mediação da aquisição de conhecimento, é necessário preparo específico que permita aos agentes, no caso deste estudo os professores de escola infantil, tal aquisição, desprovida de distorções, provenientes, por exemplo, de alguns mitos muitas vezes aceitos como verdades ${ }^{(26)}$. Entretanto, 
Quadro 2. Descrições das crianças com alterações auditivas segundo os professores entrevistados

\begin{tabular}{|c|c|c|c|}
\hline Categoria & Conteúdo & Frequência & Vinheta \\
\hline \multirow{4}{*}{$\begin{array}{l}\text { Respostas que evidenciam } \\
\text { características/comportamentos de } \\
\text { interação }\end{array}$} & Dificuldade de formação de grupos & 3 & \multirow{4}{*}{$\begin{array}{c}\text { “...ela não interage bem com os colegas, é, é uma } \\
\text { criança que fica mais no mundo dela, né, ela num tem } \\
\text { uma interação assim com as outras crianças.” }\end{array}$} \\
\hline & Isolamento & 2 & \\
\hline & Ausência de socialização & 1 & \\
\hline & Ausência de relacionamento & 2 & \\
\hline \multirow{4}{*}{$\begin{array}{l}\text { Respostas que evidenciam } \\
\text { comportamentos agressivos }\end{array}$} & Irritação & 3 & \multirow{4}{*}{$\begin{array}{c}\text { "...ela fica muito agressiva, bate em todo mundo, } \\
\text { quando não entende o que ela diz, ela fica muito } \\
\text { nervosa...” }\end{array}$} \\
\hline & Violência & 4 & \\
\hline & Nervosismo & 2 & \\
\hline & Agressão física & 7 & \\
\hline \multirow{9}{*}{$\begin{array}{l}\text { Respostas que evidenciam/ } \\
\text { comportamentos frente a atividades } \\
\text { propostas na escola }\end{array}$} & Alienação & 3 & \multirow{9}{*}{$\begin{array}{c}\text { "É no chamar e ela não responder é ficar alienada na } \\
\text { sala de aula, não, não, por exemplo prestar atenção em } \\
\text { programas musicais, brincadeiras ..." }\end{array}$} \\
\hline & Apatia & 7 & \\
\hline & Desatenção & 6 & \\
\hline & Dispersão/distração & 4 & \\
\hline & Desinteresse & 2 & \\
\hline & Mais quieta & 3 & \\
\hline & Ausência de resposta & 5 & \\
\hline & Dificuldade de compreensão & 4 & \\
\hline & Lentidão & 2 & \\
\hline $\begin{array}{l}\text { Respostas que evidenciam características } \\
\text { cognitivas }\end{array}$ & Compreende regras institucionais & 3 & $\begin{array}{c}\text { “...porque escutar ele não escuta, mas sabe de tudo, é } \\
\text { um aluno super esperto, você percebe que ele conhece } \\
\text { muita coisa, sabe das regras da escola...” }\end{array}$ \\
\hline \multirow{5}{*}{$\begin{array}{l}\text { Respostas que evidenciam utilização de } \\
\text { percepções e habilidades }\end{array}$} & Leitura labial & 1 & \multirow{5}{*}{$\begin{array}{c}\text { “...tem uma percepção visual assim, o que não } \\
\text { desenvolveu na auditiva, visual é, nossa, totalmente } \\
\text { equilibrada...” }\end{array}$} \\
\hline & Orientação espacial & 1 & \\
\hline & Visual & 1 & \\
\hline & Audição & 1 & \\
\hline & Gestos & 1 & \\
\hline \multirow{3}{*}{$\begin{array}{l}\text { Respostas que evidenciam } \\
\text { comportamentos rotineiros }\end{array}$} & Agitação & 9 & \multirow{3}{*}{$\begin{array}{c}\text { "Acho que eles são mais inquietos eles não conseguem } \\
\text { ficar muito tempo, como eles não escutam... então eles } \\
\text { ficam muitos inquietos, muito agitados." }\end{array}$} \\
\hline & Inquietação & 3 & \\
\hline & Tentativa de comunicação & 1 & \\
\hline \multirow{4}{*}{$\begin{array}{l}\text { Respostas que evidenciam } \\
\text { características/comportamentos } \\
\text { emocionais }\end{array}$} & Apego & 1 & \multirow{4}{*}{$\begin{array}{c}\text { “...é, ela fica angustiada parece, porque muitas das } \\
\text { vezes a gente não consegue entender o que ela ta } \\
\text { querendo." }\end{array}$} \\
\hline & Choro excessivo & 1 & \\
\hline & Angústia & 2 & \\
\hline & Manipulação & 3 & \\
\hline \multirow{11}{*}{$\begin{array}{l}\text { Dificuldades fonoaudiológicas e de } \\
\text { aprendizagem }\end{array}$} & Não respondem & 1 & \multirow{11}{*}{$\begin{array}{c}\text { "É o atraso da linguagem, é, a dificuldade de ta se } \\
\text { comunicando, de ta colocando o que ela quer, os } \\
\text { desejos dela..." }\end{array}$} \\
\hline & Não percebem sons & 2 & \\
\hline & Dificuldade de fala & 2 & \\
\hline & Dificuldade de compreensão & 1 & \\
\hline & Fala muito alto & 1 & \\
\hline & Dificuldade de se comunicar & 2 & \\
\hline & Atraso de linguagem & 1 & \\
\hline & Dificuldade de aprendizado & 3 & \\
\hline & Dificuldade de escrita & 2 & \\
\hline & Pronúncia errada & 1 & \\
\hline & $\begin{array}{l}\text { Dificuldade de organização do } \\
\text { pensamento }\end{array}$ & 1 & \\
\hline \multirow{2}{*}{$\begin{array}{l}\text { Respostas que evidenciam características/ } \\
\text { comportamentos frente à comunicação }\end{array}$} & Irritação & 1 & \multirow{2}{*}{$\begin{array}{l}\text { “...então pra ela se expressar, ela às vezes se irrita, } \\
\text { parece que ela quer mostrar, né alguma coisa.” }\end{array}$} \\
\hline & Impaciência & 1 & \\
\hline Não soube responder & - & 1 & $\begin{array}{c}\text { "Olha eu não tenho como ta falando, especificamente } \\
\text { pelo fato de nunca ter tido contato." }\end{array}$ \\
\hline
\end{tabular}


Quadro 3. Atitudes dos professores frente à criança com deficiência auditiva

\begin{tabular}{|c|c|c|c|}
\hline Categoria & Conteúdo & Frequência & Vinheta \\
\hline \multirow{2}{*}{$\begin{array}{l}\text { Respostas que evidenciam } \\
\text { dificuldades em decidir o que fazer }\end{array}$} & Não sabe & 5 & \multirow{2}{*}{$\begin{array}{c}\text { "A seria complicado, né, eu mesmo não to preparada } \\
\text { ainda para ta recebendo, né... teria que fazer um curso } \\
\text { né pra ta recebendo esse tipo de criança." }\end{array}$} \\
\hline & $\begin{array}{l}\text { Busca de informações em livros, } \\
\text { cursos e com profissionais }\end{array}$ & 7 & \\
\hline \multirow{5}{*}{$\begin{array}{l}\text { Respostas que evidenciam } \\
\text { uso de recursos visuais e } \\
\text { comportamentos }\end{array}$} & LIBRAS & 6 & \multirow{5}{*}{$\begin{array}{c}\text { "A gente tem curso, bastante curso que a gente faz, } \\
\text { é LIBRAS né língua de sinais e todo tipo de recursos } \\
\text { visuais." }\end{array}$} \\
\hline & Materiais visuais & 3 & \\
\hline & Leitura labial & 11 & \\
\hline & Gestos & 19 & \\
\hline & Falar olhando nos olhos & 9 & \\
\hline \multirow{6}{*}{$\begin{array}{l}\text { Respostas que evidenciam } \\
\text { mudanças na sala de aula }\end{array}$} & Falar mais alto & 2 & \multirow{6}{*}{$\begin{array}{c}\text { "Ah, eu acho que eu me expressaria bem devagar para } \\
\text { ele ler os lábios ou falar mais alto com ele." }\end{array}$} \\
\hline & Falar pausadamente & 5 & \\
\hline & Atenção individual & 4 & \\
\hline & Apoio de colegas & 1 & \\
\hline & Posicionamento da criança & 4 & \\
\hline & Evitar gritar e falar alto & 1 & \\
\hline $\begin{array}{l}\text { Respostas que evidenciam uso de } \\
\text { apoio dos outros sentidos }\end{array}$ & Tato, visão & 1 & $\begin{array}{c}\text { "Desenvolver outros sentidos que ela tem, né, e oferecer } \\
\text { estímulos pra ta crescendo isso aí." }\end{array}$ \\
\hline
\end{tabular}

entre os professores que integraram esta pesquisa, a maioria declarou nunca ter adquirido conhecimento acerca do tema em sua formação acadêmica, nem participado de oficinas ou palestras que abordassem o assunto.

Dos 12 sujeitos do estudo (27\%) que relatam já ter trabalhado com crianças com deficiência auditiva, dez apresentam pouco conhecimento sobre deficiência auditiva. Segundo afirmaram, esse conhecimento foi adquirido pelo senso comum, por meio de leituras de textos e de experiências cotidianas. Apenas dois sujeitos apresentaram informações mais completas sobre o tema, baseadas, sobretudo, nas características de crianças com deficiência auditiva.

A maioria dos entrevistados relatou que, durante a formação acadêmica, não vivenciou "embasamento teórico" algum sobre deficiência auditiva e que se sente despreparada para trabalhar com crianças que apresentem tal quadro: “...na faculdade eu não tenho nenhum embasamento teórico sobre a deficiência auditiva...”; "Eu não tenho experiência nenhuma, não conheço nada assim para trabalhar com a criança relacionada a isso, eu não conheço nada". Tais dados corroboram estudos que relataram sentimentos de despreparo para lidar com crianças com necessidades especiais ${ }^{(21,22,27)}$.

Não houve relação entre o tempo de experiência em educação infantil e as respostas que demonstram conhecimento a respeito do tema estudado, uma vez que apenas dois sujeitos $(0,9 \%)$ apresentaram respostas mais completas: um, com dois anos de experiência em educação infantil; o outro, com quinze anos.

A formação profissional dos sujeitos do estudo também não apresentou relação com o conhecimento referente ao tema. Apenas dois professores, entre os 40 que cursaram o nível superior, apresentaram respostas consideradas satisfatórias no conjunto da entrevista, ou seja, quando analisadas todas as respostas no que se refere a condutas, habilidades e competências para lidar com a deficiência auditiva ${ }^{(28)}$. Tais dados corroboram a literatura que evidenciou e discutiu o despreparo de professores para lidar com crianças com deficiência auditiva independentemente da escolaridade ${ }^{(27)}$.

Ao analisar as respostas referentes à percepção dos entrevistados acerca da deficiência auditiva (Quadro 1), identificamos as seguintes categorias: respostas que evidenciam quantidade de conhecimento; respostas apoiadas na vivência/ experiência pessoal, respostas atribuídas à vivência/experiência baseadas em ambiente de trabalho ou acadêmico; respostas fundamentadas em conceitos apoiados em senso comum; respostas apoiadas em características do surdo; respostas que revelam conceitos apoiados em alterações de audição e comunicação; respostas que demonstram conhecimento apoiado em leitura; respostas baseadas em atitudes frente ao surdo. Um dos sujeitos entrevistados não soube responder à pergunta realizada.

Cabe ressaltar que a categoria mais prevalente foi a referente à quantidade de conhecimento que os sujeitos da pesquisa possuem. Um exemplo é o seguinte relato: “...eu não tenho experiência nenhuma, não conheço nada assim para trabalhar com criança relacionada a isso. Eu não conheço nada”.

O número elevado de categorias reflete a diferenciação de percepções que os professores têm dos alunos surdos e acerca de seus próprios conhecimentos, o que corrobora os estudos em relação ao processo inclusivo de estudantes com necessidades especiais $^{(19,20,22,25,28)}$.

Entretanto, pôde-se verificar neste estudo que a grande maioria dos sujeitos entrevistados apresenta pouco conhecimento sobre a perda auditiva, muitas vezes bastante vago e de senso comum. Esse achado corrobora a literatura, quanto ao fato de o professor de escola regular não estar devidamente preparado para receber o aluno surdo e quanto a, muitas vezes, exibir idéias preconcebidas ou concepções equivocadas a respeito da deficiência auditiva ${ }^{(27)}$. A literatura, sobre a inclusão escolar de alunos surdos denota que, dentre os problemas que ocorrem no espaço escolar, o desconhecimento sobre a surdez e sobre suas implicações educacionais por parte dos professores 
é muito evidente. Desse modo, verificou-se a necessidade de aproximação entre saúde e educação nas estratégias de promoção da saúde e capacitação sobre temas afins, o que corrobora estudo anterior ${ }^{(28,29)}$

$\mathrm{Na}$ análise dos depoimentos referentes às características que os entrevistados percebem em uma criança com deficiência auditiva (Quadro 2) encontramos as seguintes categorias: respostas que apontam características e comportamentos de interação; respostas que evidenciam comportamentos agressivos, pré-concebidas; respostas que evidenciam comportamentos frente a atividades propostas na escola; respostas que apontam características cognitivas; respostas que evidenciam utilização de percepções e habilidades; respostas que evidenciam característica/comportamentos frente à comunicação; respostas que demonstram comportamentos rotineiros; respostas que evidenciam características e comportamentos emocionais, dificuldades fonoaudiológicas e de aprendizagem. Um entrevistado não soube responder a questão.

A categoria mais citada pelos entrevistados foi a referente ao comportamento apresentado pelos alunos surdos frente a atividades propostas na escola, tais como alienação, apatia, desatenção, dispersão, distração, desinteresse, ausência de resposta, dificuldade de compreensão. Vale citar: “...ela não interage bem com os colegas, é, é uma criança que fica mais no mundo dela, né, ela num tem interação assim com as outras crianças". Esses dados corroboram a literatura ao demonstrar que as dificuldades dos deficientes auditivos, mais apontadas pelos professores são relacionadas à aprendizagem, à compreensão dos conteúdos das atividades propostas e à interação, devido à falta de preparo dos professores, dificuldades com a língua portuguesa, desinteresse, apatia e dificuldade de comunicação ${ }^{(19)}$.

Houve professores que atribuíram mais de uma característica à criança com deficiência auditiva. Segundo a literatura, as características apresentadas pelas crianças deficientes auditivas são as mais variadas possíveis, por constituírem um grupo heterogêneo ${ }^{(1)}$.

Ao verificarmos para qual profissional o professor encaminharia uma criança com suspeita de deficiência auditiva, encontramos respostas bem variadas, sendo o fonoaudiólogo a indicação predominante (Figura 1). O variado número de profissionais envolvidos nos encaminhamentos mostra um desconhecimento sobre a deficiência auditiva e seus respectivos especialistas. Além disso, a grande porcentagem de encaminhamentos ao fonoaudiólogo pode ter sido influenciada pela presença das pesquisadoras durante a entrevista. Assim, os achados do presente estudo corroboram com a literatura no que diz respeito ao significativo desconhecimento sobre a deficiência auditiva e à variedade de respostas encontradas ${ }^{(1)}$.

$\mathrm{Na}$ análise do conhecimento do educador a respeito da triagem auditiva realizada em escolares percebe-se que a maioria dos sujeitos (95\%) não conhece este procedimento. Muito se tem discutido a importância dessa triagem na identificação de crianças de risco para alterações auditivas e no diagnóstico e intervenção precoce da deficiência auditiva ${ }^{(5,11,13,14,17)}$, mas a divulgação ainda não atinge a maioria dos profissionais da educação, o que pode justificar o desconhecimento do procedimento pelos entrevistados.

Ao estudarmos as respostas dos professores referentes à sua conduta, na sala de aula, com a criança com deficiência auditiva, identificamos as seguintes categorias: respostas que evidenciam dificuldades de decidir o que fazer; respostas que evidenciam uso de recursos visuais e comportamentos; respostas que apontam mudanças na sala de aula; e respostas que evidenciam uso de apoio dos outros sentidos (Quadro 3). A categoria com maior frequência foi a referente ao uso de recursos visuais e ao comportamento dos alunos surdos, tais como LIBRAS, materiais visuais, leitura labial, gestos e falar olhando nos olhos, o que nos parece ser uma forma de compensar a falta da audição nas atividades em sala, que pode ser exemplificado por: “.... gente tem curso, bastante curso que a gente faz, é libras né, língua de sinais e todo o tipo de recursos visuais".

Ressalte-se que muitos professores, inicialmente, relutaram em responder a esta questão, alegando não ter tido, ainda, experiência alguma com crianças com perda auditiva. Não sabiam responder que condutas adotariam. Sendo assim, a pergunta foi reformulada da seguinte maneira: "Se, a partir de amanhã, você passar a dar aula para uma criança com perda auditiva, qual será a sua conduta?". Esta estratégia possibilitou a reflexão dos professores sobre a questão. Os dados encontrados corroboram a literatura no que se refere às condutas adotadas em sala de aula e também na questão de que essas condutas são baseadas, na maioria das vezes, na noção de perda auditiva profunda ${ }^{(1,26,27)}$.

As condutas adotadas: colocar a criança próxima do professor, atendimento individualizado, utilizar material específico em sala de aula, falar bem articulado e conversar sempre de frente para a criança são estratégias válidas ${ }^{(30)}$, pois promovem melhor entendimento da fala do professor e da atividade a ser realizada em sala de aula.

Os temas saúde auditiva e deficiência auditiva não fazem parte da formação acadêmica do professor, sendo necessário, assim, desenvolver projetos a respeito do tema saúde auditiva e alteração da audição em escolares, a fim de promover a capacitação dos professores. Tais projetos se baseariam nos conhecimentos pregressos dos educadores e em suas necessidades e dúvidas. A falta de conhecimento em relação à deficiência auditiva e as possibilidades de intervenção despertam, entre os professores, insegurança e sentimentos de despreparo para ensinar aos alunos com deficiência auditiva.

\section{CONCLUSÃO}

Os conhecimentos, práticas e percepções a respeito da perda auditiva demonstrados pelos entrevistados revelaram grande variação dos conceitos, atitudes e estratégias. Contudo, grande parte baseia-se em senso-comum ou intuição, devido à falta de experiência e de capacitação dos educadores para lidar com a criança portadora de deficiência auditiva. 


\begin{abstract}
Purpose: To investigate the knowledge, perceptions and practices of preschool teachers regarding children with hearing alterations. Methods: A descriptive cross-sectional study was carried out through structured interviews with 45 preschool teachers from the public education system of Belo Horizonte (MG, Brazil). Interviews were recorded, transcribed and later analyzed. Results: The majority of the subjects showed little knowledge, at times vague and of common-sense, regarding hearing loss. However, conscience of the necessity of learning more about the subject for a better professional performance is clear. Despite the lack of information, teachers demonstrated knowing some characteristics of children with hearing loss, and explicit conducts to be carried out in the classroom. Almost all subjects claimed not to know the school hearing screening. Conclusion: The knowledge, practices and perceptions displayed by the subjects revealed wide variation of concepts, attitudes and strategies. However, much is based on common-sense or intuition, due to lack of experience and training of teachers to deal with children with hearing loss.
\end{abstract}

Keywords: Faculty; Child language; Childhood education; Child development; Hearing loss; Health promotion; School health

\title{
REFERÊNCIAS
}

1. Cristofolini C, Magni C. Audição: relatos e experiências de professores do ensino fundamental. Rev Fonoaudiol Bras. 2002;2(2):31-8.

2. Brasil. Casa Civil. Lei No 9394 de 20 de dezembro de 1996. Estabelece as diretrizes e bases da educação nacional. [Internet]. [citado 2009 Ago 11]. Disponível em: http://www.planalto.gov.br/ccivil_03/LEIS/19394. htm

3. Enumo SRF. Avaliação assistida para crianças com necessidades educacionais especiais: um recurso auxiliar na inclusão escolar. Rev Bras Educ Espec. 2005;11(3):335-54.

4. Gatto CI, Tochetto TM. Deficiência auditiva infantil: implicações e soluções. Rev CEFAC. 2007;9(1):110-15.

5. Nothern JL, Downs MP. Audição em crianças. 4a ed. São Paulo(SP): Manole; 2005.

6. Balbani APS, Montovani JC. Impacto das otites médias na aquisição da linguagem em crianças. J Pediatr. 2003;79(5):391-6.

7. Santos MFC, Ziliotto KN, Monteiro VG, Hirata CHW, Pereira LD, Weckx LLM. Avaliação do processamento auditivo central em crianças com e sem antecedentes de otite média. Rev Bras Otorrinolaringol. 2001;67(4):448-54.

8. Brasil. Ministério da Saúde. Política Nacional de Atenção à Saúde Auditiva Portaria No 587 de 07 de outubro de 2004. [Internet]. [citado 2009 Ago 11]. Disponível em: http://dtr2001.saude.gov.br/sas/ PORTARIAS/Port2004/PT-587.htm

9. Comitê Brasileiro Sobre Perdas Auditivas Na Infância - CBPAI. Resolução 01/99. Triagem auditiva neonatal universal. [Internet]. [citado 2009 Ago 11]. Disponível em: http://www.gatanu.org/gatanu/cbpai.php

10. Cecatto SB, Garcia RID, Costa KS, Abdo TRT, Rezende CEB, Rapoport PB. Análise das principais etiologias da deficiência auditiva em Escola Especial "Anne Sullivan”. Rev Bras Otorrinolaringol. 2003;69(2):23540.

11. Tschoeke SN, Jacob LCB, Marques JM. Estudo do diagnóstico, etiologia e (re) habilitação do deficiente auditivo em um centro da Região Sul. Tuiuti Ciênc Cult. 2008;39:63-84.

12. Instituto Nacional de Educação de Surdos - INES. Prevenção: a Audição. [Internet]. [citado 2009 Ago 11]. Disponível em: www.ines.gov.br/ Paginas/prevencao.asp

13. Botelho FA, Bouzada MCF, Resende LM, Silva CFXCA, Oliveira EA. Triagem auditiva em neonatos. Rev Med Minas Gerais. 2008;18(4 Supl 1):S139-S145.

14. Tiensoli LO, Goulart LMHF, Resende LM, Colosimo EA. Triagem auditiva em hospital público de Belo Horizonte, Minas Gerais, Brasil: deficiência auditiva e seus fatores de risco em neonatos e lactentes. Cad Saúde Pública. 2007;23(6):1431-41.
15. Penteado RZ, Servilha EAM. Fonoaudiologia em saúde pública/coletiva: compreendendo prevenção e o paradigma da promoção da saúde. Distúrb Comun. 2004;16(1):107-16.

16. Temporini ER. Percepção de professores do Sistema de Ensino do Estado de São Paulo sobre o seu preparo em saúde do escolar. Rev Saúde Pública. 1988;22(5):411-21.

17. Vieira ABC, Macedo LR. O diagnóstico da perda auditiva na infância. Pediatria(São Paulo). 2007;29(1):43-9.

18. Freire RM. Fonoaudiologia em saúde pública. Rev Saúde Pública. 1992;26(3):179-84.

19. De Vitta FCF, Silva KPL, Moraes MCAF. Conceito sobre a educação da criança deficiente, de acordo com os professores de educação infantil da cidade de Bauru. Rev Bras Educ Espec. 2004;10(1):43-58.

20. Malvão AA, Barcellos CAP, Freitas VA. Educação inclusiva: a diversidade faz parte da vida: o papel do professor como protagonista do processo inclusivo. Janus. 2006;4(2):21-62.

21. Smeha LN, Ferreira IV. Prazer e sofrimento docente nos processos de inclusão escolar. Rev Educ Espec. 2008; 31:37-48.

22. Monteiro, APH; Manzini EJ. Mudanças nas concepções do professor do ensino fundamental em relação à inclusão após a entrada de alunos com deficiência em sua classe. Rev Bras Educ Espec. 2008;14(1):35-52.

23. Ramos AS, Alves LM. A fonoaudiologia na relação entre escolas regulares de ensino fundamental e escolas de educação especial no processo de inclusão. Rev Bras Educ Espec. 2008;14(2):235-50.

24. Bardin L. Análise de Conteúdo. Lisboa: Edições 70; 1977.

25. Armond JE, Temporini ER. Crenças sobre saúde ocular entre professores do sistema público de ensino no município de São Paulo, SP-Brasil. Rev Saúde Pública. 2000;34(1):9-14.

26. Duboc MJO. Formação do professor, inclusão educativa: uma reflexão centrada no aluno surdo. Sitientibus. 2004;31:119-30.

27. Silva ABP, Pereira MCC. O aluno surdo na escola regular: imagem e ação do professor. Psicol Teor Pesqui. 2003;19(2):173-6.

28. Lacerda CBF. A inclusão escolar de alunos surdos: o que dizem alunos, professores e intérpretes sobre esta experiência. Cad CEDES. 2006;26(69):163-84.

29. Gonçalves FD, Catrib AMF, Vieira NFC, Vieira LJES. A promoção da saúde na educação infantil. Interface Comun Saúde Educ. 2008;12(24):181-92.

30. Guarinello AC, Berberian AP, Santana AP, Massi G, Paula M. A inserção do aluno surdo no ensino regular: visão de um grupo de professores do Estado do Paraná. Rev Bras Educ Espec. 2006;12(3):317-30. 
Anexo 1. Entrevista

Qualificação profissional:

Tempo de experiência em Educação Infantil:

1- O que você conhece sobre a deficiência auditiva?

2- Você já trabalhou na sala de aula com crianças portadoras de deficiência auditiva?

3- Que características você percebe em uma criança com essa deficiência?

4- Para qual profissional você encaminharia uma criança com suspeita de deficiência auditiva?

5- Você conhece a triagem auditiva realizada em crianças em idade escolar?

6- Qual a sua conduta, na sala de aula, para com uma criança com deficiência auditiva? 